\title{
Welcome Address - from the Editors
}

You have just opened the first issue of Heart Drug ${ }^{\mathrm{TM}}$. We at the editorial desk welcome you to this new journal. Heart Drug ${ }^{\mathrm{TM}}$ is a journal with a special mission: to focus on cardiovascular clinical trials. With the launch of every new journal, however, the question arises: does the community really need yet another one?

Cardiovascular diseases are the most common cause of hospitalization and the predominant contributor to mortality in the Western world. With dramatic increases in population age, the socioeconomic impact of cardiovascular disorders, as well as their contribution to the decrease in quality-adjusted life-years, is predicted to be a major concern well into the new millennium.

In the wake of this pandemic development, the challenge of curing patients with cardiovascular disorders has attracted some of the brightest minds to the field. Some of these spearheading researchers and clinicians have been instrumental in accelerating novel therapy concepts arising from both basic and clinical science. Consequently, cardiovascular medicine is one of the most rapidly evolving fields today.

Scientists and publishers around the globe are aware of the increasing significance of cardiovascular medicine in the publishing arena. New journals are being launched, many of which attempt to cover whatever potential authors might wish to submit and future subscribers might accept to read. Thus, some of these products claim to encompass almost every topic, from congenital disease to cardiovascular nursing, from intensive care equipment evaluation to behavioral sciences, from hospital evaluation programs to molecular pharmacology. We, however, feel that the core of the art of cardiovascular medicine is represented by the clinicians actively involved in research and performing clinical trials. They are the ones who thoroughly study basic concepts and boldly test them in clini- cal settings; the ones who carry the burden of conducting large-scale cardiovascular trials, waiting for years, if not decades, for follow-up results; the ones who put forth challenging hypotheses and continuously assess their therapeutic impact.

These are the people who deserve a new, state-of-theart cardiovascular journal - Heart Drug ${ }^{\mathrm{TM}}$. This will be a journal in which excellence in clinical science and the courage to take concepts from the bench to the bedside receive the highest priority; a journal which copes with the challenge of presenting negative results; a journal which exclusively devotes itself to providing a forum for cardiovascular specialists - from pursuit of their ideas to presenting their final results - and deals with everything in between: novel approaches to increasing patient enrollment, appropriate forms of presenting results and much more. Above and beyond that, we will aim to bring together industry and academia, government experts and statistical consultants to share their views in order to improve the quality of clinical investigations, and to speed up information exchange.

We are proud to introduce this journal to the global cardiovascular community, as we are strong believers in the advancement of this exciting field. We will do everything in our power to provide a forum of the highest quality for researchers with a strong drive to achieve clinical results. We are aiming at a rapid review process based on a network of forefront experts in cardiovascular disease, and immediate coverage by all major citation machineries. Please enjoy reading and publishing in Heart Drug $^{\mathrm{TM}}$

Dan Atar, Copenhagen

Hideo Kusuoka, Osaka

Victor L. Serebruany, Baltimore, Md.

\section{KARGER}

Fax + 41613061234

E-Mail karger@karger.ch www. karger.com (c) 2000 S. Karger AG, Basel

Accessible online at: www. karger.com/journals/hed 